Journal of Accident and Emergency Medicine 1994

11, 21-24
Correspondence:

B.A. Lewis, Social Worker, Accident and Emergency Department, Burnley General Hospital, Casterton Avenue, Burnley BB10 2PQ

\title{
The role of the social worker in the accident and emergency department of a district general hospital
}

\author{
B.A. LEWIS, W.A.MCNABB \& S.U.RAHMAS \\ Accident and Emergency Department, Burnley General Hospital, Burnley
}

\section{SUMMARY}

This is a retrospective study of the development of the social worker role within the multi-disciplinary team setting of the Accident and Emergency (A\&E) Department at Burnley General Hospital over a 2year period from October 1989 to October 1991.

Key words: crisis, liaison, presence, preventative, pro-active.

\section{INTRODUCTION}

Failure to address social problems leads to deteriorating social functioning, which may result in both physical and psychological ill-health. ${ }^{1}$

By having an active presence in the department, the social worker is more readily available to identify areas of need and to develop an effective system of referral and intervention. As a result, a pro-active, preventative social work service can be established with opportunities for the development of specialized services, not traditionally perceived as part of the social work role.

\section{HISTORICAL PERSPECTIVES}

Few hospitals already have a social worker operating exclusively within the A\&E Department. In the past at Burnley General Hospital, social work support was provided by the duty Social Worker who was based elsewhere. A preliminary assessment of social problems had to be made by nursing and medical staff before referral to the Social Work Department. This was not only time consuming for staff, but often resulted in the use of alternative and inappropriate routes of referral. In consequence, an ineffectual system for requesting social work support had developed and referral to the Social Work Department was low. This reflected more upon the inadequacies of the system, than an absence of need.

Nursing and medical staff were of the opinion that the social needs of patients attending the department were not being met adequately and the appointment of a specialist social worker for the unit was considered to be a solution to this problem. ${ }^{2}$

At the beginning of October 1989 the specialist post of Social Worker for the A\&E Department and allied clinical areas became operational.

The exact nature of the role of the Social Worker in the Department was not clearly defined at this stage, and the quantity of work could not be predicted. The only certain factor was that the workload would be of a 'generic' nature (social services definition), with the following key patient groups already identified as requiring service development:

(1) the vulnerable elderly

(2) those suffering sudden disability as a result of injury

(3) children at risk ${ }^{3,4}$

(4) those suffering from alcohol and other substance abuse and dependency

(5) the mentally ill

(6) those involved in acts of deliberate self-harm;

(7) those suffering from injuries during domestic violence

(8) those exhibiting evidence of social disfunction, e.g. anxiety related disorders.

Service development was not to be confined exclusively to these patient groups, and the potential for social work involvement in other areas was acknowledged.

\section{DEVELOPMENT OF THE SOCIAL WORK ROLE}

The primary objective for the A\&E Social Worker was to develop a system whereby social problems experienced by patients attending the department could be identified and addressed. This was regardless of whether they had arisen as a direct result of the injury to which treatment was being given, or were of some other origin, but had become evident during a medical assessment in the A\&E Department. 
B.A. Lewis et al.

Therefore, the first task was to establish an effective means of referral to enable a more detailed evaluation of social circumstances to be made by the Social Workers, when necessary.

A message system was introduced in order to pass on non-urgent information out of office hours, while the Emergency Duty Team were available for urgent referrals. During office hours, direct referral to the Social Worker occurred.

It was evident immediately and probably reflective of the type of service previously provided for the department, that referrals related mainly to elderly people who were in need of practical support following injury. Awareness of the range of services that could be made available through the A\&E Social Worker was very limited, which resulted in the occasional failure to refer other equally pressing cases. $^{5,6}$

However, by being present in the department and 'offering' social work support where appropriate, the A\&E Social Worker was able to demonstrate a wider role.

Through continual feedback and discussion with the nursing and medical staff, it was soon possible to identify those areas of difficulty in which the Social Workers could effectively intervene and those which were beyond the scope of their resources.

After a 3-month period the recorded referrals were examined and evaluated. The key patient groups who were previously identified as requiring service development had indeed become the focus of the social work service.

In addition, a more specific service has been developed to meet the needs of two other groups of people who attend the A\&E Department. These are patients who have deliberately harmed themselves, and the suddenly bereaved.

Attitudes towards patients who had deliberately harmed themselves, particularly the repeated attenders, were perceived as being rather ambivalent, and the emotional needs of these patients were often overlooked.

Consideration was given to the possibility that providing these patients with, support at a time of crisis could, in some cases, enable alternative coping strategies to be developed and thereby interrupt the cycle of events that results in repeated incidents of deliberate self harm. ${ }^{7}$

Nursing staff were encouraged to make some attempt to identify whether or not these patients were experiencing difficulties with which they required some help, and then to refer patients to the Social Worker as appropriate.
The provision of continuing social support to the suddenly bereaved has been a major development in A\&E medicine. ${ }^{8}$ Death in the A\&E department is particularly difficult for families to deal with because it usually involves a sudden illness or injury and was completely unexpected. 9,10

With the introduction of on-site Social Workers it became possible to extend the care and support given to grieving relatives within the A\&E Department, out into the community. The Social Workers may visit families at home and can arrange longterm counselling when required.

As a result of this, a continuing service has been developed with the Social Workers as key members of a professional Bereavement Care Team. ${ }^{11,12}$

\section{RESULTS AND DISCUSSION}

The workload of an A\&E Department is unpredictable and the number of patients attending the department varies continually.

Examination of the referral rate has been limited to the observation of trends. Data on the referral rate from the unit prior to the commencement of the social work post was limited. The total number of referrals for the 12-month period from October 1988 to September 1989 was 19, with four of those relating to patients admitted to the observation beds.

With the provision of 'on-site' social work support and the increasing awareness of the social work role, there was a substantial increase in the overall referral rate (Tables 1 and 2).

The fact that some patients will have received more than one form of service provision accounts for the discrepancy in the 'Total' figures in Tables 1 and 2.

Intervention and disposal was divided into four main categories: (1) immediate short term crisis centred support by A\&E Social Workers; (2) referral for continuing Community Care by area-based Social Workers; (3) provision of residential care for those unable to return home, but not requiring hospital admission; and (4) referral for further assesment or longer term support from other agencies.

Table 1 illustrates that a large proportion of referrals relate to the need for immediate crisis centred support. However, the greatest number of referrals relate to disposal categories (2) and (4), indicating that many patients were found to be experiencing chronic difficulties, not exclusively related to an immediate crisis or medical trauma, which required long term intervention.

Table 2 shows that the greatest number of refer- 
Role of the social worker in A\&E
Table 1. Number of referrals relating to four main categories of intervention and disposal

\begin{tabular}{lccr}
\hline & $\begin{array}{c}\text { October 89- } \\
\text { September } 90\end{array}$ & $\begin{array}{c}\text { October } 90- \\
\text { September } 91\end{array}$ & Total \\
\hline $\begin{array}{l}\text { Support by } \\
\text { A\&E Social Worker }\end{array}$ & 151 & 186 & 337 \\
$\begin{array}{l}\text { Referral to } \\
\text { Community Care }\end{array}$ & 151 & 78 & 229 \\
$\begin{array}{l}\text { Services } \\
\text { Residential } \\
\text { Care }\end{array}$ & 12 & 12 & 24 \\
$\begin{array}{l}\text { Referrals to } \\
\text { and liaison with } \\
\text { other Agencies }\end{array}$ & 535 & & 780 \\
\begin{tabular}{l} 
Total \\
\hline
\end{tabular} & 849 & 245 & \\
\hline
\end{tabular}

rals (somewhat predictably) relate to the $75+$ age group. However, there has been a consistent rate of referral relating to the other age groups, reflecting the fact that as awarencess was increased, the role of the Social Worker became extended.

The overall referral rate dropped significantly in the second year. There are two factors which are known to have contributed to this. Firstly, the process of recording was changed so that referrals relating to patients who were subsequently admitted to hospital wards were recorded as part of the Ward Social Workers statistics and not the A\&E Department Social Workers statistics as had been the case in the first year. Secondly, the number of inappropriate referrals was reduced when initial enthusiasm to refer all elderly patients and then all non-medical problems was moderated by an improved understanding of the social work role.

The number of referrals to the Bereavement Care

Table 2. Referral to A\&E social workers categorized by age

\begin{tabular}{lccr}
\hline Age & $\begin{array}{c}\text { October 89- } \\
\text { September } 90\end{array}$ & $\begin{array}{c}\text { October } 90- \\
\text { September } 91\end{array}$ & Total \\
\hline $0-12$ & 67 & 32 & 99 \\
$13-16$ & 69 & 14 & 83 \\
$17-44$ & 185 & 64 & 249 \\
$45-64$ & 73 & 39 & 112 \\
$65-74$ & 56 & 43 & 99 \\
$75+$ & 249 & 121 & 370 \\
Total & 699 & 313 & \\
\hline
\end{tabular}

Team indicates that the introduction of this service was well received.

Access to short term observation beds has proved to be essential for patients who may be placed at risk by immediate discharge from the A\&E department.

This facility has been of particular benefit to the $75+$ age group, however, the overall figures show an increased tendency to admit to observation beds.

Table 3. Provision of bereavement care service

\begin{tabular}{lc}
\hline Age & November $90-$ September 91 \\
\hline $0-5$ & 14 \\
$5-16$ & 2 \\
$17-44$ & 13 \\
$45-64$ & 7 \\
$65-74$ & 7 \\
$75+$ & 9 \\
& 52 \\
\hline
\end{tabular}

Table 4. Use of observation beds

\begin{tabular}{lc}
\hline Age & October $89-$ September 91 \\
\hline $17-44$ & 3 \\
$45-64$ & 4 \\
$65-74$ & 1 \\
$75+$ & 14 \\
& 22 \\
\hline
\end{tabular}


B.A. Lewis et al.

In 12 out of 22 cases, the Social Worker was involved in the decision to admit. In addition to this, by ensuring the provision of continued Social Services support, the Social Workers were able to facilitate prompt discharge, thus preventing the misuse of short-term beds for primarily social welfare reasons.

Information relating to incidents of deliberate selfharm is limited because there are many variables which influence the degree of social work involvement required and whether or not a formal referral was made. During a sample period in August 1990, 120 incidents of deliberate self-harm were referred to the Social Worker. In most cases, patients were admitted to hospital for observation and further assessment. For those discharged, follow-up support in the community was provided when necessary.

\section{CONCLUSIONS}

The introduction of a Social Worker into the A\&E Department at Burnley General Hospital has resulted in the establishment of an effective and efficient system to deal with patients who are in need of social assessment and service provision and has enabled the development of a service to groups of patients previously overlooked, for example, the suddenly bereaved, patients with selfinflicted injuries and those suffering from anxiety disorders. In consequence, an improved social work service is now being offered to those attending the A\&E Department, not only within the department but by appropriate referral to other agencies in the community.

Although cost effectiveness cannot be measured directly, a social work presence in the A\&E Department has relieved the nursing and medical staff from the responsibility of attending to socially orientated problems, which may be sufficient justification for the provision of a specialist social worker.
The preventative element incorporated into this type of work again cannot be measured easily, but the authors believe that early referral to the Social Worker has reduced the number of patients returning to the department as a result of previously unmet social needs.

The provision of an 'on-site' social work service may prove to be an important element in improving the quality of patient care in the A\&E department.

\section{REFERENCES}

1. Croner E. (1978) Delivery of social work services in the emergency room. A description of an existing program. Social Work Health Care 9, 720.

2. Bell U. (1988) A fairer deal. Nursing Times 84, 43.

3. Perry R. (1987) Highlighting child abuse. Community Care.

4. Thornton B., Pierson J. \& Kent P. (1990) Guide to the Children Act 1989. Community Care 19 April, vii.

5. McDonald A.J. \& Abrahams S.T. (1990) Social emergencies in the elderly. Emergency Medicine Clinics of North America 8(2), 442.

6. Dove A.F. \& Dave S.H. (1986) Elderly patients in the accident department and their problems. British Medical Journal 292, 807.

7. Newson-Smith Hirsch S.R. (1979) A comparison of social workers and psychiatrists in evaluating para suicide. British Journal Psychiatry, 203.

8. Yates D.W., Ellison G. \& McGuinness S. (1990) Care of the suddenly bereaved. British Medical Journal 301, 86.

9. Walters D.T. \& Tupin J.P. (1991) Family grief in the emergency department. Emergency Medicine Clinics of North America 9, 193.

10. Kubler-Ross E. (1969) On Death and Dying. McMillan, New York.

11. Wright B. (1991) Sudden Death. Churchill Livingstone, Edinburgh.

12. Wright B. (1991) Caring in Crisis. Churchill Livingstone, Edinburgh. 


\section{Erratum}

Volume 11, Number 1 1994, pp 21-24

The role of the social worker in the accident and emergency department of a district general hospital

B.A.LEWIS, W.A.MCNABB \& S.U.RAHMAN

The authors would like to correct an error, which occurred in the above paper. The third author is S.U. Rahman and not S.U. Rahmas as published. 